\title{
Gender and Aging in the Developing World: Where Are the Men?
}

JOHN KNODEL

MARy Beth Ofstedal

IN RECENT YEARS, both population aging and gender have become prominent issues in international forums concerning population, as well as important areas of academic inquiry for social demography. Interest in gender often focuses on inequalities that disadvantage women, while much of aging research focuses on the economic and social vulnerability of older persons. Thus it is not surprising that the discourse related to both topics refers mainly to women and emphasizes their potential disadvantage in old age. It is frequently asserted or implied that older women are universally more vulnerable to social, economic, and health disadvantages than older men.

\section{The one-sex view of gender}

Perhaps the most significant manifestation of this exclusive concern with women when considering gender and aging is the Madrid International Plan of Action on Ageing, emanating from the Second World Assembly on Aging sponsored by the United Nations in 2002 (United Nations 2002). The assembly took place amid considerable fanfare and publicity, in the tradition of other large international UN conferences and world summits on key issues such as population, environment, human settlements, women, and social development. It was clearly the most important international meeting on the issue of aging to occur since the first World Assembly on Ageing was convened in Vienna two decades earlier. The Plan of Action is likely to have widespread influence on policy and programs throughout the world, especially in developing countries, where many governments have only re- 
cently recognized the inevitable population aging they will face in the coming decades and are only now formulating strategies to deal with it.

The Plan explicitly advocates "the integration of a gender perspective into all policies, programmes and legislation" dealing with aging (United Nations 2002: paragraph 8). The very same paragraph, however, states that "the situation of older women everywhere must be a priority for policy actions," making clear that concerns about gender really mean concerns about women. Over 40 statements in the document either stress the particular vulnerability of older women with respect to virtually every major aspect of well-being or advocate that particular attention be given to women in programs and policies directed toward improving the lot of the elderly population. In contrast, there is not a single statement recognizing that older men may have special needs, much less any recommendations advocating particular attention to older men on any issue. ${ }^{1} \mathrm{~A}$ similar identification of gender and aging solely with issues affecting women is evident in the Final Declaration and Recommendations of the World NGO Forum on Ageing, held in conjunction with the Second World Assembly on Aging (see the section on gender in Global Action on Aging 2002: 3).

The impression that older women are disadvantaged compared to older men in all settings and in all aspects of well-being is likewise given by the limited section on older persons incorporated in the 1994 Programme of Action of the International Conference on Population and Development (ICPD) held in Cairo (United Nations 1995: paragraphs 6.16-6.20). Key documents issued by the United Nations Population Fund (UNFPA), an organization that played an important role in the preparations for both the Cairo conference and the Second World Assembly on Aging, further reinforce this view. Both the 1998 and 2000 UNFPA State of the World Population reports make clear that a "gender-sensitive approach to aging" involves emphasizing exclusively the wide variety of aspects in which older women are assumed to be at a disadvantage (UNFPA 1998, 2000). For example, the 2000 report highlights seven gender-specific issues related to aging, all of which emphasize the needs of older women. Moreover, the report of an Expert Group Meeting convened by the UNFPA as part of the preparatory activities for the Second World Assembly on Aging is replete with statements calling attention to special needs of older women without any mention of needs specific to older men (UNFPA 2002a). Similar emphases are found in other UN publications and numerous other reports (e.g. UN ESCAP 1996, 1997; UN INSTRAW 1999; UNFPA 2002b). Indeed, in all these documents, the possibility that older men might be the disadvantaged sex in any respect is never acknowledged except, as discussed below, in the curious way that men's shorter longevity is seen as a circumstance contributing to women's plight but not as a problem for men.

Is the exclusive emphasis on older women in a gender-sensitive approach as advocated by the Madrid International Plan of Action and in the 
rhetoric of the UNFPA and other UN agencies justified? Are older women truly disadvantaged globally in all or most essential aspects of well-being. thus obviating the need for any special concerns about older men? Unfortunately much of the limited academic research on gender and aging has also focused only on women (Gibson 1996; Mehta 1997). Nevertheless sufficient evidence exists to call into question the wisdom and equity of a virtually exclusive emphasis on the needs of women when incorporating gender concerns into policies and programs related to aging. Much of this evidence is actually contained in UN reports prepared in conjunction with the Second World Assembly on Aging.

We do not suggest that the special needs of older women should be ignored, nor do we deny that women may be disadvantaged in more ways and in more settings than older men. Rather we argue that a gender-sensitive approach should consider the special needs of both sexes and also recognize that gender is not always a compelling marker of disadvantage. We restrict our focus to the developing regions of the world. This is where the vast majority of older persons live, particularly those whose level of vulnerability to economic and health disadvantage is high. It is also where policies on population aging are often still in a nascent and formative state and more likely to be shaped by recommendations from the Madrid International Plan of Action and other UN forums. Most data that we present refer to the population aged 60 and older, the ages that are most commonly used to define the older populations in developing countries.

\section{Theoretical perspectives on gender and aging}

McMullin (1995: 30) has pointed to a remarkable "lack of theoretical development concerning the relationship between gender and ageing." The most common theoretical perspective within which issues related to gender and aging are treated is that of the life course, with a stress on linkages between gender differences at earlier and later stages (Hatch 2000). The life course perspective explicitly recognizes changes in statuses and roles as persons age and hence can highlight how changes, such as from married to widowed or employed to retired, can differentially affect men and women as they pass through their older years. The assumed relative disadvantage of elderly women is related to differences in men's and women's earlier life experiences, including the different economic and caregiving roles they have filled and the different rewards they have received (Hooyman 1999). These in turn are "shaped by various structures and relations of privilege and inequality, including those of gender" (UN INSTRAW 1999: ix). As one UN Bulletin on Ageing postulates, for women "lifelong oppression and discrimination reduce access to essential resources and result in higher rates of illness and poverty in late life" (Pratt 1997: 2). This life course perspective is called on repeatedly in the Madrid Inter- 
national Plan of Action and in UNFPA publications to justify the emphasis on concerns about older women rather than older men. For example, according to the Second World Assembly on Aging, "For women, a life course approach to well-being in old age is particularly important, as they face obstacles throughout life with a cumulative effect on their social, economic and psychological well-being in their later years" (United Nations 2002: paragraph 64).

A major weakness in the application of the life course approach to gender and aging has been the almost exclusive focus on linkages between later life circumstances and earlier conditions in which women are disadvantaged. Ignored are any earlier circumstances that might lead to female advantage and corresponding male disadvantage in later life. In some settings, mothers in old age may command greater emotional loyalty from their adult children than do fathers, in part in recognition that mothers have sacrificed more in raising their children and in part because closer emotional bonds may develop between mothers and children during childhood (e.g., Aboderin, forthcoming and 2003; Risseeuw 2001; Wolf 1972). Women may also experience greater role continuity as they enter old age compared to men, who commonly experience role disruption associated with exit from paid work or other productive activities (Beales 2000; Gibson 1996). Similarly, older women may be more valued as members of multigenerational households than nonworking elderly men because of the greater contribution women make to domestic chores, in accordance with lifelong roles that assign them primary responsibility in this sphere of activities (Beales 2000; Lopata 2002). In contrast, men may be more likely to experience feelings of rejection or reduced self-esteem when they are no longer able to earn a living. In some settings, men may also be less likely to have sustained networks of social support, especially if they had relied heavily on social interaction in the work place for such support during their working years (WHO 2001: 6).

Somewhat different but not inconsistent with the life course perspective, particularly in the manner it has been applied, is the commonly argued "double jeopardy" hypothesis. According to this view, the negative effects of occupying two stigmatized statuses - that is, being female and oldcombine to make older women a particularly disadvantaged group who are in "double jeopardy" (Chappell and Havens 1980). This argument is reflected in the UNFPA's 1998 State of the World Population report, which states that older women "bear the burden of age-old negative perceptions, which is added to the customary social and economic discrimination against women" (UNFPA 1998: 58). A contrary argument, however, sometimes referred to as the "age-as-leveler" hypothesis, has also been advanced. In this view, gender inequality is seen as declining in old age, since all elderly persons are subject to physical decline and other negative forces regardless of gen- 
der (Markides and Black 1995). Some ethnographers of Arab societies even argue that "women acquire increasing status in their communities and increasing familial authority and power as they accrue important markers of gender identity over the life course, including marriage, motherhood, and the marriage of sons and daughters" (Yount, forthcoming). Indeed, not just in the Arab world but in many societies where patrilocal residence is common, older women may have increasing power by gaining authority as mothers-in-law over younger women who marry into the household. Such circumstances would contribute to an even greater reduction in gender inequality during old age compared to earlier life course stages.

Conceptual discussions of links between gender and aging typically ignore the possibility that the direction of gender inequalities or its absence may vary for different dimensions of support or well-being (e.g., Lopata 1987; Mehta 1997; UN INSTRAW 1993). Particularly problematic is the general lack of recognition given to the wide variation in cultural, political, and socioeconomic contexts that determine both gender relations and old-age support and the likelihood that their interrelationships will differ across the settings within which they play out.

\section{The demographic argument}

One common justification for emphasizing women over men when considering gender and aging is that women dominate numerically at older ages. This argument is clear in both the Madrid and Cairo (ICPD) plans of action (United Nations 2002: paragraph 3; United Nations 1995: paragraph 6.16). Straightforward statements to this effect are included in a UNFPA report produced in preparation for the Second World Assembly on Aging: "In most countries, older women greatly outnumber older men. In many cases, the differences are so significant that the concerns of the older population should, in fact, be viewed primarily as a concern of older women" (UNFPA 2002a: 11). According to a statement by two senior UNFPA staff in the same report, "in all societies, older women far outnumber older men" (ibid.: 13). Even the latest U.S. Census Bureau report on global aging asserts, "Continuing or growing disparities in sex ratios mean that many of the challenges faced by the elderly of today and tomorrow are, in essence, challenges and problems faced by older women" (Kinsella and Velkoff 2001: 59).

Indeed in the vast majority of national populations, women do outnumber men at ages 60 and older. But the extent to which they do so is far more moderate, especially in the developing world, than the bold assertions cited above suggest. The top panel of Figure 1 shows the percent male among the population aged 60 and older in regions of the developing world for the year 2000, based on UN Population Division estimates contained in a special volume issued in conjunction with the Second World Assembly 
FIGURE 1 Sex composition of the older population in the developing world

A. Percent male among the population aged 60 years and older by region
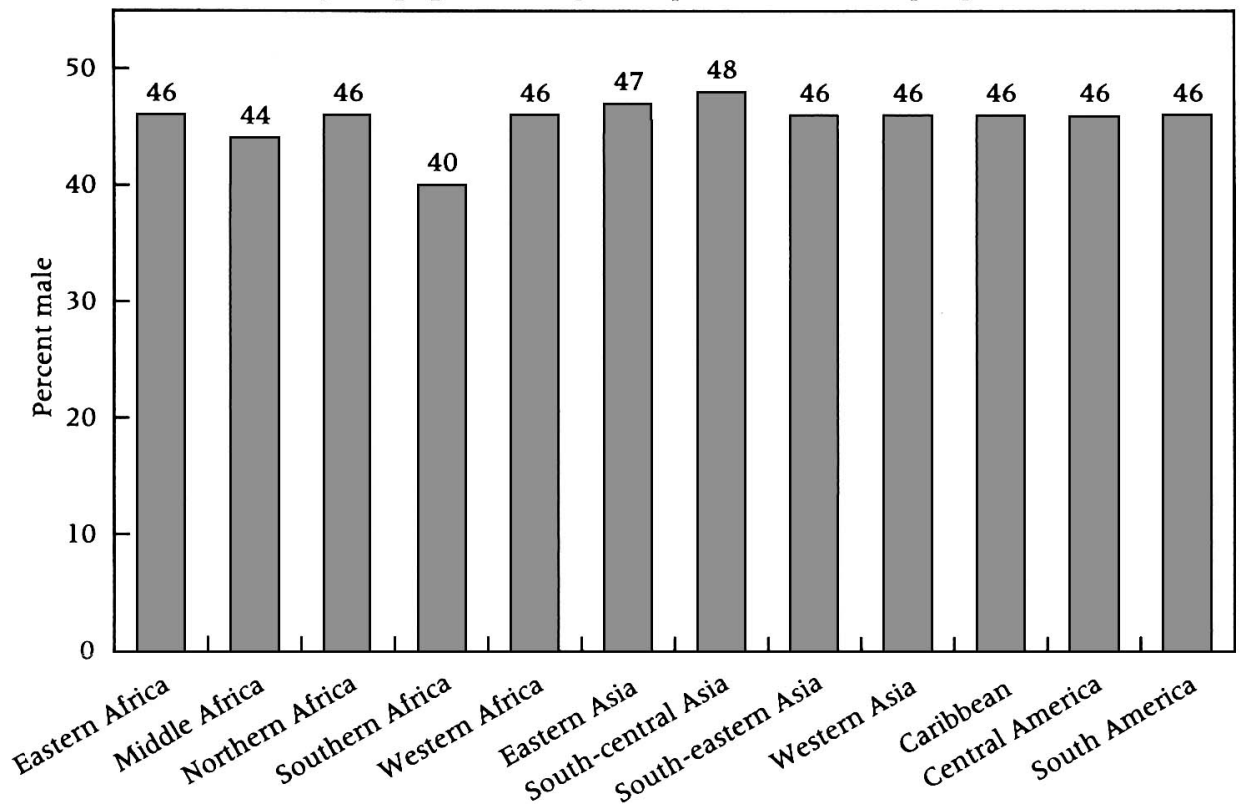

B. Percent male by age group (left axis) and percent of age group as a percent of the population aged 60 years and older (right axis), developing regions, 2000

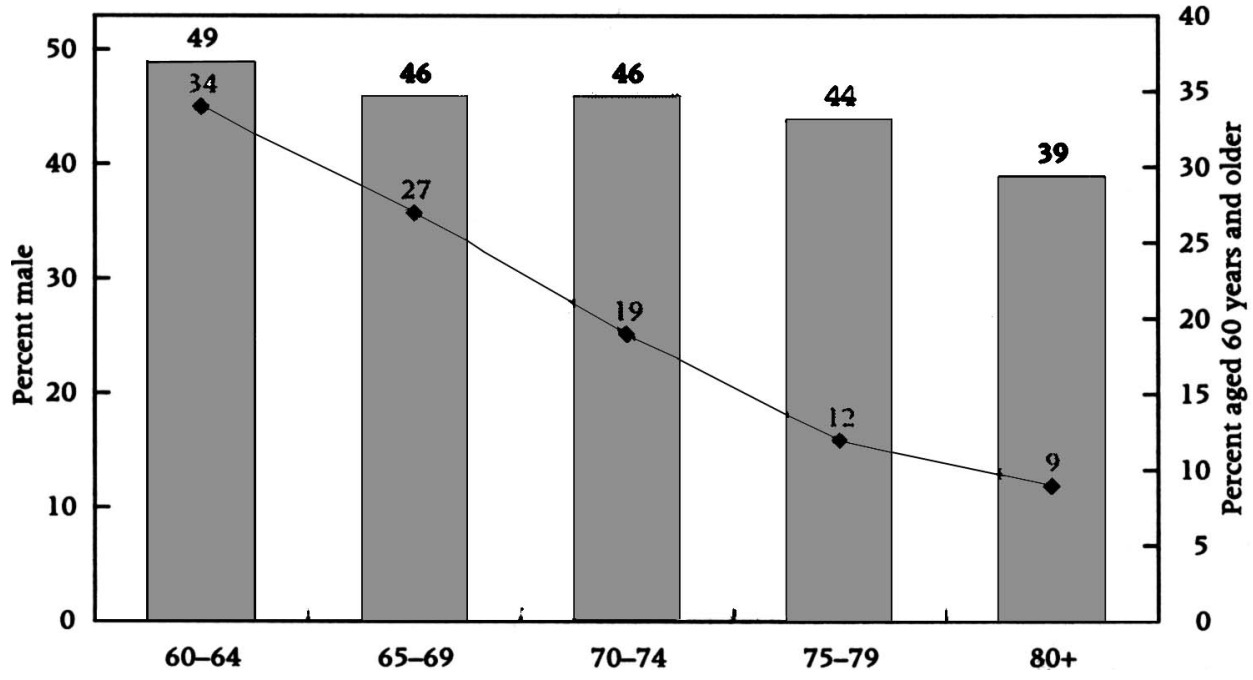

SOURCE: United Nations Population Division 2002.

on Aging (United Nations Population Division 2002). In all regions men constitute less than half of the older population. In several regions, they are just a few percentage points below 50 percent, and in all but two of the 12 
regions men constitute more than 45 percent of the population aged 60 and older. Such a large share hardly merits dismissal as insignificant.

Statements justifying an emphasis on older women in considerations of population aging frequently stress that their numerical dominance is "especially true in the case of the oldest old" (UNFPA 2002a: 11). Indeed, men represent a declining share of successively older age groups among the elderly, as shown in the bottom panel of Figure 1. Still, men account for well over 40 percent of each age group through ages 75-79. Even among the population aged 80 and older, men constitute almost two-fifths of the total. Also ignored by those who advocate a focus on women is that, although the share of women increases as we move from the younger old to the older old, the demographic significance of each successive age group sharply declines. As the bottom panel of Figure 1 also shows, in the year 2000 the age group 80 and older constituted less than a tenth of all persons aged 60 and older in the developing world. In contrast, more than a third are under age 65 , among whom men are almost as numerous as women.

More compelling than the numerical supremacy of older women compared to older men is the wide gender gap in marital status. Typically most older men are currently married while most older women are widowed. A special assessment made in 1999 by the UN Population Division in connection with the International Year of Older Persons estimated that 78 percent of older men compared to only 43 percent of older women in the developing regions were currently married (United Nations Population Division 1999). The International Programs Division of the U.S. Census Bureau recently reviewed available census data on the topic (Kinsella and Velkoff 2001). Among the 30 countries in the developing regions for which data are provided, the most recent censuses indicate that in most countries only 10 to 20 percent of men aged 65 and older were widowed compared to over half of the women in the same ages. ${ }^{2}$ Older women are far more likely to be widowed than older men because women typically live longer than men, marry men who are older than themselves, and are less likely than men to remarry.

The lack of a spouse can often make life more difficult for an elderly person. Whether losing a spouse leads to more adverse consequences for men or for women likely varies with the social, economic, and cultural setting. However, the fact that older women are far more likely to be widowed than men virtually everywhere predisposes them disproportionately to any associated disadvantages. Commonly mentioned in this connection is the increased chance of living alone as a result of widowhood, with the implication that this in turn leads to greater social and economic vulnerability. For example, one UNFPA report states that "large numbers of older women live alone either because they are unmarried or widowed," and the next paragraph mentions that older "women without a partner are perceived to 
be economically and socially vulnerable" (UNFPA 2002b: 8-9). Likewise the Second World Assembly on Aging viewed women living alone as being in urgent need of social protection measures (United Nations 2002: paragraph 53b). It also sees widowed women as particularly prone to poverty (paragraph 46). Widowed older women are also seen to be socially isolated. One UNFPA report goes so far as to state that "Gender issues result from women increasingly being alone at older ages..." (UNFPA 2002a: 19).

Census data generally confirm that older women are more likely to live alone than older men, although substantial regional variation is evident in both the overall tendency to live alone and the size of the gender gap. A review of international census data from 1990 to 1999 by the U.S. Census Bureau provides statistics on the percent of elderly women and men living alone for 13 developing countries (Kinsella and Velkoff 2001: 65). In 11 of the 13, the share of women living alone exceeded that of men, and the unweighted average is 10 percent of men and 16 percent of women. An earlier review of census data from 19 developing countries from the $1980 \mathrm{~s}$ also indicated that elderly women were more likely to live alone than elderly men, with the unweighted averages being 14 percent of men and 17 percent of women (UN INSTRAW 1993). However, a special report by the UN Latin American and Caribbean Center of Demography (CELADE) issued in conjunction with the Second World Assembly on Aging shows no systematic gender gap in the percent of the populations 60 and older who live alone in 19 Latin American countries. According to the most recent data for each country, the percentage living alone was higher among older women in nine countries but lower in nine others (with equal percentages in one country). Also the percentage living alone was generally low for both sexes, with the unweighted average being just under 9 percent for both men and women. Interestingly, in all 19 countries, among the elderly who are not married or in a consensual union, the percentage who live alone is substantially higher among men than women, with the unweighted averages being 28 versus 14 percent (CELADE 2002: Table 26).

Even granted that older women in the developing world are more likely to live in solitary households than older men, the assumption that this is a clear marker of disadvantage is not as well established as much of the discourse would suggest. While some elderly women and men who live alone are isolated or even deserted, many others are not. Recent analyses for the Philippines, Thailand, and Vietnam reveal that most elderly persons in solitary households are far from being deserted by their children, kin, or other persons (Natividad and Cruz 1997; Knodel and Chayovan 1997; Knodel and Saengtienchai 1999; Truong et al. 1997). In many cases, adult children or close kin live in adjacent dwellings or near by. Census statistics miss such situations since they typically describe only the composition of the immediate household narrowly defined. Still, having a spouse present has advantages for most elderly persons compared to being widowed, whether or not 
others also live in the household. This can be of particular importance in times of illness or frailty when caregiving is required. That widowhood rates are far higher among women than men thus correctly implies that "older men can rely on their wives for care more than vice versa" (UNFPA 1998: 57).

\section{Gender and health}

One almost universal gender gap among older populations, found in nearly every country in the developing as well as developed world, is the mortality gap. Older men die earlier than older women virtually everywhere. The top panel of Figure 2 shows UN estimates of the female advantage in life expectancy among older persons in regions of the developing world for the period 2000-05. On average, women who reach age 60 can expect to live 2.7 years longer than men. In none of the regions shown is the female advantage in old-age survival less than a full year, and in Eastern Asia, where 45 percent of the elderly population of the developing world live, life expectancy at age 60 for women exceeds that for men by more than four years. Moreover, as the bottom panel of Figure 2 shows, the UN projects that women's advantage in life expectancy at age 60 will increase for the developing world as a whole by almost a year over the next half century.

What gender gap could be more serious than this one, which is literally a matter of life and death? Yet nowhere in the Madrid or Cairo (ICPD) plans of action or in the various discussions of aging in UNFPA reports is it suggested that particular attention be given to improving male survivorship. As noted above, rather than being portrayed as a disadvantage for men, lower male life expectancy is presented instead as a disadvantage for women by stressing that older women must endure long periods as widows. Even given this view, the total lack of attention to reducing the male disadvantage in survival is remarkable since improving older-age survivorship among men would seem to be a logical way to reduce widowhood among older women.

A biological component to the sex differential in mortality has been well established. Some might use this as a justification to argue that it is "natural" that women outlive men and that, to determine which sex is disadvantaged with respect to mortality, it would be necessary first to discount men's "natural" disadvantage. We do not deny that there are biological influences on the gender gap in life expectancy at birth and at later ages, but these necessarily interact with both environmental and socially and culturally influenced behavioral factors that vary over time and setting (Doyal 2001; Nathanson 1984; Verbrugge and Wingard 1987; Waldron 1985, 1995). Hence it is misleading to assume that observed differences between the sexes in survival are preordained. For example, risk behaviors such as smoking and drinking have been shown to be strongly associated with excess male mortality, and in many settings these behaviors likely account for a sub- 
FIGURE 2 Women's advantage (the "gender gap") in life expectancy at age 60 in the developing world

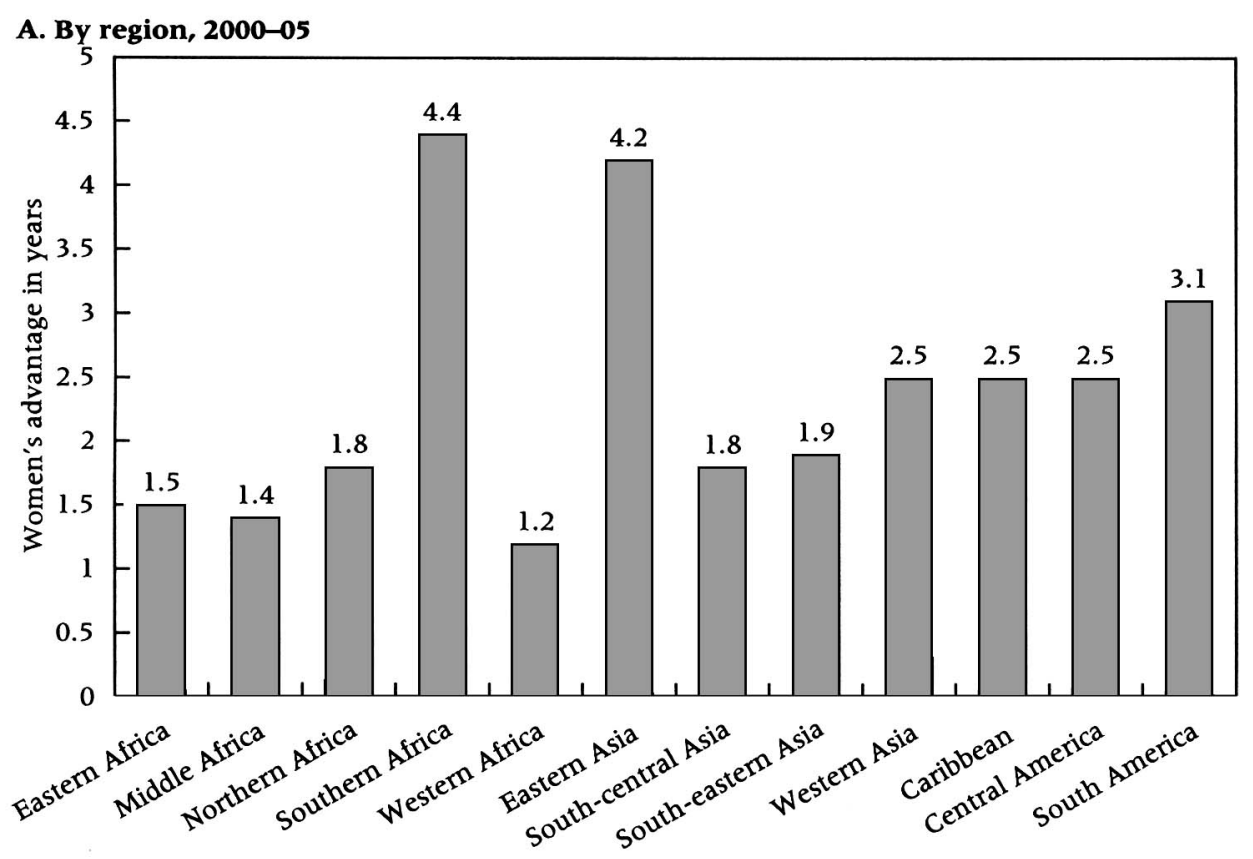

B. By continent, 2000 to 2050

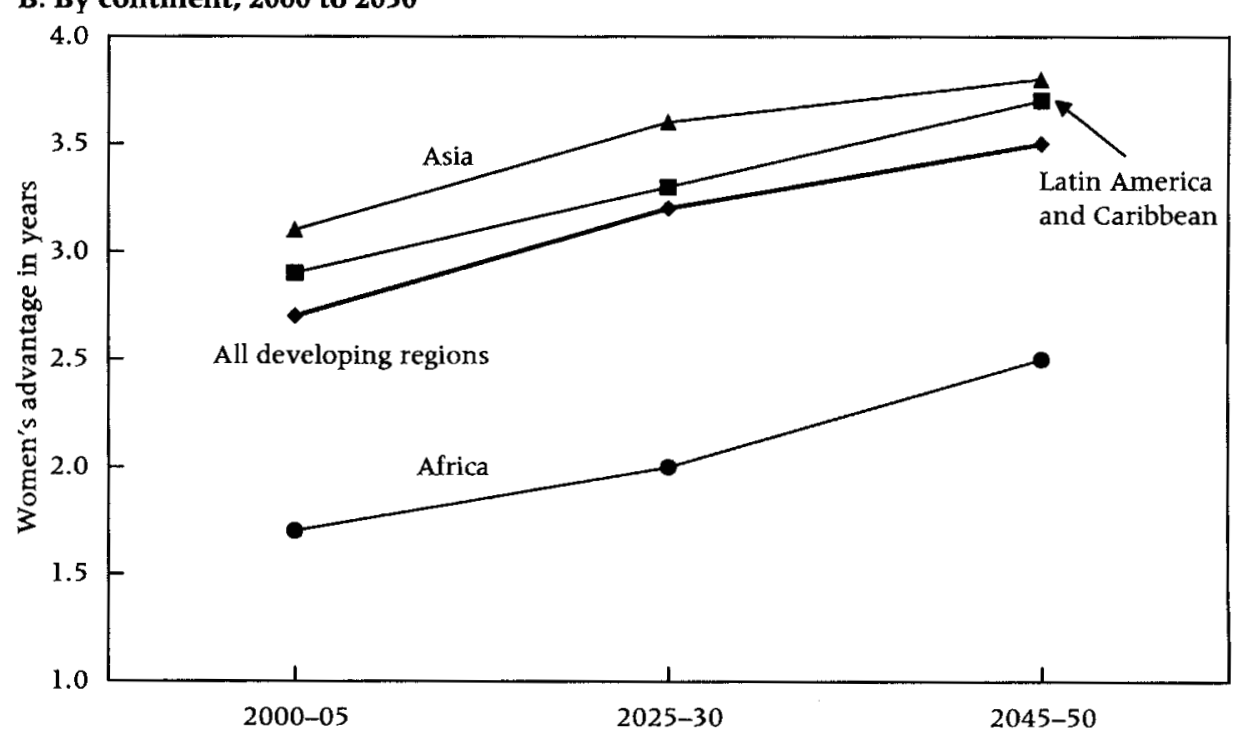

SOURCE: United Nations Population Division 2002.

stantial share of gender differences in adult mortality (Bobak 2003; Pampel 2002; Waldron 1986). An argument that men are genetically programmed to be more prone to risk taking than women would hardly justify assuming 
that smoking or drinking excessively is either natural or immutable. Indeed there is ample evidence that these behaviors can be modified. Since men are more likely than women to engage in such behaviors, interventions targeted at men seem warranted. Similar arguments can be made with regard to hazardous occupational and environmental exposures and psychosocial stress, which also contribute to excess male mortality (Nathanson 1984).

In our view, gender-specific influences that disadvantage men with respect to survival and health should be addressed just as those that operate to women's disadvantage deserve attention. Yet, when health issues are treated in relation to gender and aging, as a recent WHO report notes, typically only the health problems and needs of elderly women are emphasized (WHO 2001: 1). According to the Second World Assembly on Aging, "Older women are particularly vulnerable to disability in old age due to, inter alia, gender differences in life expectancy and disease susceptibility and gender inequalities over the life course" (United Nations 2002: paragraph 87). The ICPD recommends developing "systems of health care...paying special attention to women" (United Nations 1995: paragraph 6.17). The report of the UNFPAsponsored preparatory meeting for the Second World Assembly on Aging highlighting gender issues contains an entire section on "special health needs of elderly women" as well as global generalizations such as "older women in particular still suffer from health-related problems" (UNFPA 2002a: 36). Nowhere in the report, however, are special health needs of older men mentioned. Likewise, the 1998 State of the World Population report contains a chapter titled "Adding years to life and life to later years" in which one might think the male disadvantage in old-age life expectancy would logically receive attention. Instead, all gender-specific concerns raised focus solely on women, as do all the "gender-differentiated indicators" of health at older ages that are recommended for adoption (UNFPA 1998: 73-84). The justification is that "women generally live longer than men but they can also expect more years of ill health late in life" (ibid.: 74).

There is indeed considerable evidence to suggest that, on balance, women are more likely to experience non-life-threatening illnesses and health problems than are men and that this holds at most life stages including at older ages. Most studies are from developed countries and refer to a number of indicators, including overall self-rated health, functional impairments, and disabilities (Verbrugge 1985, 1989; Verbrugge and Wingard 1987). Similar, but more limited evidence is available for developing countries (Palloni, PintoAguirre, and Pelaez 2002; Rahman et al. 1994; Sobieszczyk, Knodel, and Chayovan 2003; WHO 200I; Zimmer et al. 2002: 7). Almost all the studies rely on self-reported data and thus may be affected by gender-based perceptions of health. One common concern is that, at least in some social and cultural settings, women may be more aware of their health problems or more willing to report them than men (Doyal 2001; MacIntyre, Hunt, and Sweeting 1996; Nathanson 1975; Verbrugge 1985, 1989). If so, the apparent gender 
gap may be overestimated. Nevertheless, the preponderance of evidence points to a higher prevalence of nonlethal illness and disabilities among older women than older men and justifies inclusion of this recognition in a gender-sensitive approach to issues related to aging. However, it by no means justifies the lack of attention to the male disadvantage in the life-threatening diseases and conditions that result in higher male mortality at older ages. Moreover, gender is but one of several dimensions that differentiate health at older ages and not necessarily the most important one. Low socioeconomic status is typically a powerful and robust predictor of poor health (National Research Council 2001: 221). It would be unfortunate if the current focus on gender in international forums and in programs of multinational organizations were to divert attention from targeting the health needs of older persons who are in the least favorable socioeconomic situations regardless of their sex.

\section{Social and economic well-being}

One dimension on which the current generation of older women in most developing countries is clearly disadvantaged compared to men is formal education. On the basis of data for 105 developing countries, the UN Population Division (2002: 31 ) estimates that among the population aged 60 and older in 2000, 69 percent of women and 41 percent of men were illiterate. Both the levels and size of the gender gap in illiteracy are projected to decline over subsequent decades through cohort succession, reflecting trends toward increased schooling and gender equality in school entry (see also Hermalin 2002). A gender gap in achieved schooling levels also exists among older populations in virtually all developing countries. For example, according to recent data for urban populations in 14 Latin American countries and for rural populations in nine, men aged 60 and older averaged more years of schooling than did women in all but one rural population (CELADE 2002: Table 14). The difference, however, was typically moderate. According to unweighted averages, rural men had only 0.4 more years of schooling than rural women, while in the urban populations the male advantage averaged one additional year. Data for eight Asian countries also indicate higher levels of educational attainment among older men than older women, with a more pronounced gap in most than is typical in Latin America (Ofstedal, Reidy, and Knodel 2003). ${ }^{3}$

Women's lack of access to education is cited by the Second World Assembly on Aging as contributing to their poverty in old age, presumably in comparison to men (United Nations 2002: paragraph 109). The UNFPA points out that lower literacy and numeracy among older women make them particularly vulnerable to exploitation in financial and legal transactions (UNFPA 2002a: 58). In a discussion of the employability of older workers and their need to adapt to new demands and opportunities, the $\mathbb{L O}$ mentions the lack of basic literacy and numeracy among older women as an important consid- 
eration (ibid.: 68-69). Such reasoning likely underlies the fact that in the actions recommended by the Second World Assembly on Aging to improve access to knowledge, education, and training for older persons, women are singled out three times for special attention (United Nations 2002: paragraph 40).

While a gender gap clearly exists with regard to education, less clear are the implications of this for gender differences in well-being among older persons in the developing world. Little or no education is surely a disadvantage in numerous respects. It is important to recognize, however, that the rapid expansion of education in most developing countries during the last half century means that even older men today have quite limited levels of education compared to younger adults, and thus suffer a severe competitive disadvantage relative to younger cohorts. Moreover, most older men who did attend school in the past typically received only a primary education (see e.g. Ofstedal, Reidy, and Knodel 2003; UN INSTRAW 1993). ${ }^{4}$ This is unlikely to provide much of an advantage in obtaining attractive jobs in today's formal sector or to be of much assistance in coping with the ways information technology is transforming daily living. Thus, the recommendation by the Second World Assembly on Aging to "ensure that the benefits of new technologies, especially information and communication technologies, are available to all, taking into account the needs of older women," seems shortsighted in not recognizing the considerable needs that older men are likely to have in this regard as well.

The lower education of older women clearly contributes to gender differences in employment histories-particularly employment in the government and formal sectors that affects access to work-related pensions-and hence is potentially an important factor in gender differences in economic well-being. Indeed, the most pervasive theme in justifying special attention to older women in discussions of population aging is that they are assumed to be economically disadvantaged compared to older men. Well over half of the statements in the Madrid International Plan of Action that single out older women for particular concern or actions relate wholly or in part to their assumed economic disadvantage. Global generalizations to this effect are common. Typical is a UNFPA statement asserting that "Older women's need for support is deep as well as widespread in developing countries. They are more likely than men to be poor" (UNFPA 2002a: 58). As the Second World Assembly on Aging makes clear, this disadvantage is assumed to be the outcome of numerous forces operating over the life course: "Poverty and low income during women's earning years can often lead to poverty in old age"; or "Factors affecting older women in the labour market deserve special attention, in particular those factors that affect women's engagement in paid work, including lower salaries, lack of career development due to interrupted work histories, family care obligations and their ability to build pensions and other resources for their retirement" (paragraph 25).

While the logic of such arguments may appear compelling, the relative economic well-being of older women compared to older men is a mat- 
ter to be determined through empirical investigation. A major challenge in attempting such an investigation is that economic well-being is a multidimensional concept, and focusing on one indicator (e.g., individual income) can give a misleading picture (Hermalin, Chang, and Roan 2002). First, there may be genuine variation across different dimensions of economic wellbeing (e.g., an individual with low personal income may live in a household that is quite wealthy in terms of household income, assets, and possessions). Second, economic well-being, at least as perceived by older persons themselves, depends not just on resources that are directly monetary in nature, such as earnings or interest income, but also on nonmonetary resources that bear on an older person's material circumstances, such as the presence of other family members and the person's own ability to perform tasks that save money (Arber and Ginn 1991; Danigelis and Mclntosh 2001). Third, some components contributing to economic well-being may be difficult to measure, particularly in developing countries where subsistence agriculture and employment in the informal sector loom large. Further complicating measurement are two common situations: where elderly individuals are part of a multigenerational household that functions largely as a single consumptive unit and where the elderly receive material support in kind, as well as through monetary remittances from non-coresident adult children or relatives. Indeed in many developing countries, familial support is still the mainstay for most elderly (World Bank 1994).

A common finding in developing countries is that older men are more likely than older women to receive income from work-related pensions. This is the case, for example, in all seven Asian countries that are included in a recent cross-national study (Ofstedal, Reidy, and Knodel 2003). Among the urban populations in the 16 countries and the rural populations in the ten countries in Latin America for which recent data are provided by CELADE, older men were more likely than older women to receive retirement pensions or other allowances in all but one case (CELADE 2002: Table 18). The unweighted averages among the population aged 60 and older indicate that $4 \mathrm{I}$ percent of urban men compared to 27 percent of urban women and 23 percent of rural men compared to 16 percent of rural women received income from some sort of pension or allowance. Nevertheless, although a particular person, such as a retired man, may be the one receiving the pension, other family members, and particularly his wife, may well benefit from it. Indeed it seems likely that for most elderly couples, income would be used jointly regardless of who receives a particular pension or allowance. Depending on survivorship benefits, however, a wife could lose much of the shared benefit if her husband predeceased her, which commonly is the situation.

The report by CELADE also provides statistics on the incidence of poverty among persons 60 and older for all but one of the urban populations 
and all the rural populations in Latin America referred to in the previous paragraph (CELADE 2002: Table 16). Presumably, this measure reflects the net effect of various forms of income and support. In contrast to the situation with respect to receipt of income from pensions or allowances, the gender gap in poverty is far less consistent. Overall the proportion of elderly below the poverty line ranged widely, from 2 percent among the urban elderly in Uruguay to 77 percent among the rural elderly in Honduras. However, as Figure 3 shows, gender differences were typically modest and could be in either direction. Among the 15 countries with data for urban populations, where over 80 percent of the elderly in Latin America are found, in six a higher share of elderly men were below the poverty line than women. Moreover in none of the nine countries where women were more likely to be poor does the ratio of the percent of women to the percent of men in poverty exceed 1.14. A more consistent female disadvantage is apparent among the rural elderly, with higher percentages of women below the poverty line in all but two of the ten countries with relevant data. Even on this indicator, however, the ratio of the percent of women to the percent of men in poverty is less than 1.2 in all countries except one. The unweighted means for the percent of women and men in poverty are almost the same for urban populations ( 31 versus 30 percent) and quite close for rural populations ( 47 versus 44 percent). The CELADE report also indicates the proportion of older women and men who are in severe poverty. The pattern is similar to that for poverty in general, with the unweighted means for urban women and men both being 12 percent and for rural women 26 compared to 23 percent of men.

Findings from Asia, too, suggest that gender differences in economic well-being may be more modest than the discourse on gender and aging typically assumes. Recent surveys for five countries provide information on self-assessed income adequacy or satisfaction. Such subjective measures of economic well-being may be even more telling than specific objective measures because they allow respondents to take into account the various aspects of their economic situation and express the net result as they perceive it (Chan, Ofstedal, and Hermalin 2002). As Figure 4 shows, among the five countries with available data, only in Vietnam do older women appear to be substantially worse off than men on this broad measure of economic well-being. ${ }^{5}$ In the other four countries, differences are modest and sometimes even to the disadvantage of men. In addition, a recent survey of the oldest old in China, a country where over a third of the developing world's elderly live, reveals that although women were substantially less likely to receive a pension than men, gender differences in self-reported life satisfaction were negligible (Zeng, Liu, and George 2003). While life satisfaction will obviously reflect many dimensions of well-being, one's economic situation is likely to be part of this. 
FIGURE 3 Ratio of the percent of older women to the percent of older men living in poverty, 1996-98

A. Urban populations of 15 Latin American countries

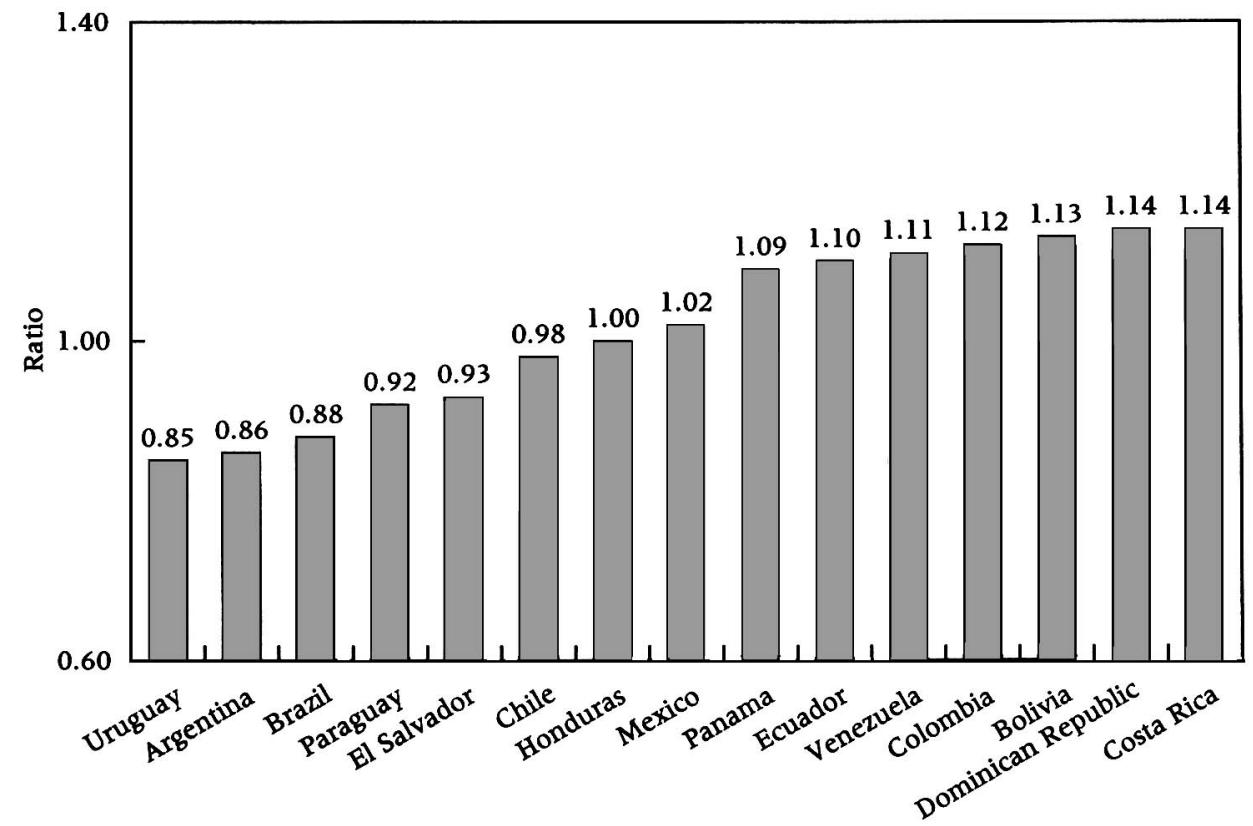

B. Rural populations of ten Latin American countries

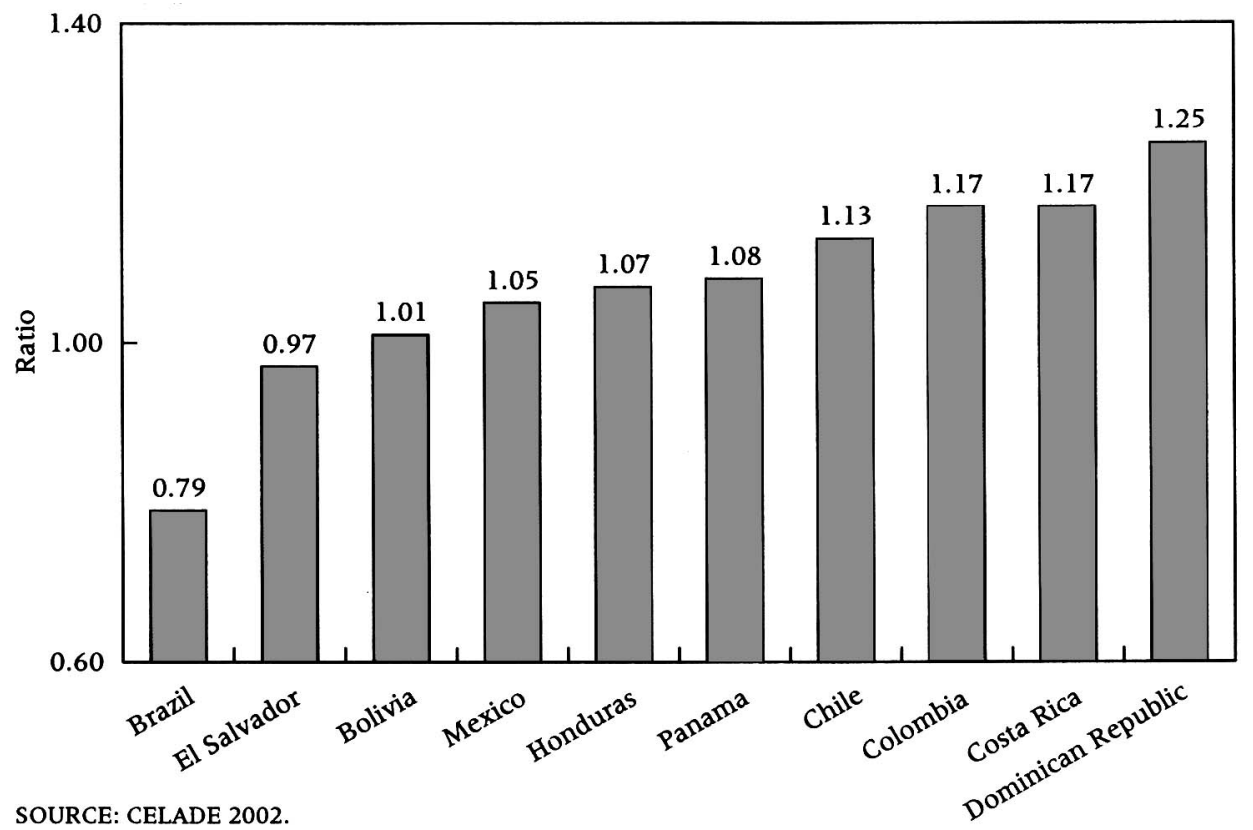


FIGURE 4 Percent of men and women aged 60 and older who state that their income is at least adequate, 1995-96

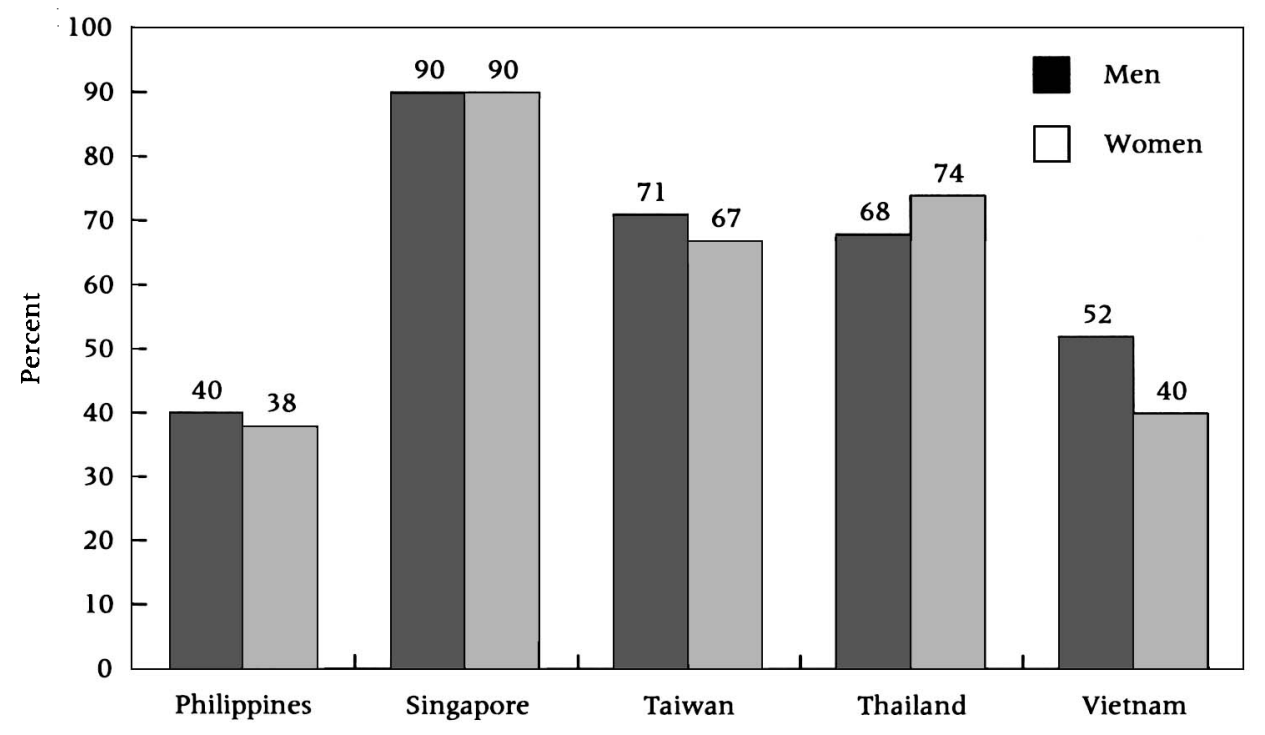

SOURCE: Ofstedal, Reidy, and Knodel 2003.

\section{Conclusions}

In many settings, perhaps even in most, older women may be disadvantaged relative to older men on some or most dimensions of well-being. Clearly, too, there are numerous exceptions as indicated by the examples presented above. A major hindrance to making a more definitive statement about gender and aging is that systematic empirical assessments comparing the situation of older men and women are inadequate for drawing a firm conclusion-especially for the developing world, where the large majority of older persons live. Most broad statements asserting a generalized female disadvantage in old age appear to be based on presumptions and an incomplete allowance for the full set of influences over the life course, including later stages, that determine well-being in old age. In any event, generalizations about which sex is more disadvantaged are of limited value. To more fully understand the effects of gender on the well-being and support of older persons and their families, research must move beyond assumptions of universal gender inequality and the disadvantaged situation of older women to examine the experiences of older men and women within the contexts in which they live. Such research should recognize that well-being at older ages is multidimensional and that gender differences may go in either direction or, for that matter, be largely absent, depending on the aspect of well-being under consideration. Distinguishing settings and circumstances 
in which older women are truly disadvantaged from those where they are not, or in which women may in fact be advantaged, and understanding the basic determinants of these differences are requirements for the development of sound policies incorporating a gender dimension. Future research on gender and aging hopefully will provide the basis to do so.

The many generalizations about women's disadvantage in old age that are explicit or implicit in the Madrid International Plan of Action that emanated from the Second World Assembly on Aging and numerous statements and reports of the UNFPA and other international agencies show remarkably little willingness to acknowledge that the relationship between gender and aging varies across settings and over time. Such global statements are more suggestive of a predetermined agenda than of an interest to examine the situation as it actually is. Indeed, some may see the exclusive emphasis on older women whenever gender issues are considered in relation to population aging as conforming to the UN millennium development goal to "promote gender equality and empower women" (United Nations General Assembly 2001). To us, however, the complete lack of consideration of circumstances where older men are disadvantaged seems remarkably onesided and contradictory to the ideals of gender equity. As often noted, the ICPD in Cairo represented a virtual paradigm shift in which matters related to women became of central importance for guiding population-related policy and programs (McIntosh and Finkle 1995). It appears that efforts to impose a similar shift with regard to population aging are underway. ${ }^{6}$

The tendency to elevate gender above virtually all other markers of disadvantage in old age, especially when gender considerations are limited to those that relate only to one of the two sexes, is likely to be counterproductive if the problems and needs of the world's elderly population are to be effectively addressed. In some situations, measures especially targeted toward older women will indeed be called for. But a more balanced perspective that recognizes gender as a potential, but not necessarily central marker of vulnerability for various aspects of well-being in specific settings and times, and that allows for male as well as female disadvantage to be addressed, would seem a far better way to serve the current and future elderly generations.

\section{Notes}

This research is supported by the grant "Gender and Aging: Asian Evidence" from the Rockefeller Foundation.

1 As one reviewer of this article points out, UN declarations such as the Madrid International Plan of Action tend to be vague, using terms such as "focus on" and "emphasize" without spelling out what is recommended. Some of the recommendations appear to be based on an unrealistic model that would have developing-country governments adopting measures found in a Western-style welfare state. While this may be an important and legitimate criticism of the Madrid International Plan of Action, it is beyond the scope of the present analysis to consider in detail.

2 For two of the 30 countries, the statistics referred to the population aged 60 and older. 
3 Although Ofstedal, Reidy, and Knodel (2003) provides the percentages completing different levels of education and thus cannot be compared directly with the CELADE results, a larger gap can be inferred from the pronounced gender differences in the distributions of achieved levels.

4 This is also obvious from the low average number of years of completed study among men reported by CELADE, which indicates an unweighted mean of less than six years for older urban men and just over two years for older rural men (CELADE 2002).

5 For Thailand the results shown refer to a question that asked about satisfaction with one's current economic situation; in all others results refer to a question on adequacy of income.

6 It is encouraging to note that the one large international nongovernmental organization that focuses on aging, namely HelpAge International, takes a far more balanced view of gender and aging than characterizes the Madrid International Plan of Action or UNFPA reports. In their State of the World's Older People report prepared for distribution at the Second World Assembly on Aging, the discussion of gender and aging starts by pointing out that "women and men experience ageing in different ways, and face different problems and relative disadvantages in old age" and elaborates on this theme (HelpAge International 2002: 8). This represents a considerable shift from their earlier Aging and Development Report in which the entire chapter devoted to gender and aging focused only on women's concerns (HelpAge International 1999: 33-45).

\section{References}

Aboderin, Isabella. 2003. "Intergenerational family support and old age economic security in sub-Saharan Africa. The importance of understanding shifts, processes and expectations," in Peter Lloyd-Sherlock (ed.), Living Longer: Aging, Development and Social Protection. London: ZED Books.

Aboderin, Isabella. Forthcoming. "Modernization and economic strain: The impact of social change on material family support for older people in Ghana," in V. L. Bengtson and A. Lowenstein (eds.), Families, Aging and Social Supports: International Perspective. Hawthorne, NY: Aldine de Gruyter.

Arber, Sara and Jay Ginn. 1991. Gender and Later Life: A Sociological Analysis of Resources and Constraints. London: Sage Ltd.

Beales, Sylvia. 2000. "Why we should invest in older women and men: The experience of HelpAge International," Gender and Development 8(2): 9-18.

Bobak, Martin. 2003. "Relative and absolute gender gap in all-cause mortality in Europe and the contribution of smoking," European Journal of Epidemiology 18(1): 15-28.

Centro Latinamericano y Caribeño de Demografía (CELADE). 2002. Los Adultos Mayores en América Latina y El Caribe: Datos e Indicadores. Santiago de Chile: CELADE.

Chan, A., M. B. Ofstedal, and A. Hermalin. 2002. "Changes in subjective and objective measures of economic well-being and their interrelationship among the elderly in Singapore and Taiwan," Social Indicators Research 57: 263-300.

Chappell, Neena and Betty Havens. 1980. "Old and female: Testing the double jeopardy hypothesis," The Sociological Quarterly 21 (Spring 1980): 157-171.

Danigelis, N. and B. McIntosh. 2001. "Gender's effect on the relationships linking older Americans' resources and financial satisfaction," Research on Aging 23(4): 410-428.

Doyal, Lesley. 2001. "Sex, gender and health: The need for a new approach," British Medical Journal $323(7320)$ : 1061-1063.

Gibson, Diane. 1996. "Broken down by age and gender: 'The problem of old women' redefined, "Gender $\theta$ Society 10(4): 433-448.

Global Action on Aging. 2002. Final Declaration and Recommendations of the World NGO Forum on Ageing. New York: Global Action on Aging.

Hatch, Laurie R. 2000. Beyond Gender Differences: Adaptation to Aging in Life Course Perspective. Amityville, NY: Baywood Publishing. 
HelpAge International. 1999. The Ageing Development Report. London: HelpAge International.

- 2002. State of the World's Older People 2002. London: HelpAge International.

Hermalin, Albert. 2002. "Capturing change: Transitions at older ages and cohort succession," in Albert Hermalin (ed.), The Well-Being of the Elderly in Asia: A Four Country Comparative Study. Ann Arbor, MI: University of Michigan Press, pp. 519-541.

Hermalin, A. I., M-C. Chang, and C. Roan. 2002. "Economic well-being: Insights from multiple measures of income and assets," in A. I. Hermalin (ed.), The Well-Being of the Elderly in Asia: A Four-Country Comparative Study. Ann Arbor, MI: University of Michigan Press, pp. 295-360.

Hooyman, Nancy R. 1999. "Untapped resources: Women in ageing societies across Asia," Gerontologist 39(1): 115-118.

Kinsella, Kevin and Victoria Velkoff. 2001. An Aging World: 2001. Washington, DC: US Government Printing Office.

Knodel, John and Napaporn Chayovan. 1997. "Family support and living arrangements of Thai elderly," Asia Pacific Population Journal 12: 51-68.

Knodel, John and Chanpen Saengtienchai. 1999. "Studying living arrangements of the elderly: Lessons from a quasi qualitative case study approach in Thailand," Journal of Cross-Cultural Gerontology 14(3): 197-220.

Lopata, Helena Z. (ed.). 1987. Widows: The Middle East, Asia, and the Pacific. Durham: Duke University Press. 566 .

MacIntyre, S., K. Hunt, and H. Sweeting. 1996. "Gender differences in health: Are things really as simple as they seem?," Social Science Medicine 42 (4): 617-624.

Markides, Kyriakos and Sandra Black. 1995. "Race, ethnicity and aging: The impact of inequality," in Robert Binstock and Linda George (eds.), Handbook of Aging and the Social Sciences, 4th ed. New York: Academic Press.

McIntosh, Alison and Jason L. Finkle. 1995. "The Cairo Conference on Population and Development," Population and Development Review 21(2): 223-260.

McMullin, Julie. 1995. "Theorizing age and gender relations," in Sara Arber and Jay Ginn (eds.), Connecting Gender and Ageing: A Sociological Approach. Bristol, PA: Open University Press, pp. 173-199.

Mehta, Kalyani. 1997. Untapped Resources: Women in Ageing Societies. Times Academic Press: Singapore.

Nathanson, Constance. 1975. "Illness and the feminine role: A theoretical review," Social Science Medicine 9; 57-62.

- 1984. "Sex differences in mortality," Annual Review of Sociology 10: 191-213.

National Research Council. 2001. Preparing for an Aging World: The Case for Cross-National Research. Washington, DC: National Academy Press.

Natividad, Josefina and Grace Cruz. 1997. "Patterns in living arrangements and familial support for the elderly in the Philippines," Asia-Pacific Population Journal 12(4): 17-34.

Ofstedal, Mary B., Erin Reidy, and John Knodel. 2003. "Gender differences in economic support and well-being of older Asians," Population Studies Center Research Report 03350, November. Ann Arbor, MI: University of Michigan.

Palloni, Alberto, Guido Pinto-Aguirre, and Martha Pelaez. 2002. "Demographic and health conditions of ageing in Latin America and the Caribbean," International Journal of Epidemiology 31 : 762-771.

Pampel, Fred. 2002. "Cigarette use and the narrowing sex differential in mortality," Population and Development Review 28(1): 77-104.

Pratt, Clara C. 1997. "Ageing: A multigenerational, gendered perspective," Bulletin on Ageing 2(3): 1-9.

Rahman, M. O., John Strauss, Paul Gertler, Deanna Ashley, and Kristin Fox. 1994. "Gen- 
der differences in adult health: An international comparison," The Gerontologist 34 (4): 463-469.

Risseeuw, Carla. 2001. "Policy issues of inclusion and exclusion in relation to gender and ageing in the South," The European Journal of Development Research 13(2): 26-48.

Sobieszczyk, Teresa, John Knodel, and Napaporn Chayovan. 2003. "Gender and well-being among the elderly: Evidence from Thailand," Ageing $\theta$ Society 23(6): 701-735.

Truong Si Anh, Bui The Cuong, Daniel Goodkind, and John Knodel. 1997. "Living arrangements, patrilineality, and sources of support among elderly Vietnamese," Asia Pacific Population Journal 12(4) (4): 69-88.

United Nations. 1995. Population and Development Volume I Programme of Action Adopted at the International Conference on Population and Development, Cairo, 5-13 September 1994. ST/ ESA/SER.A/149. New York: United Nations.

- 2002. Report of the Second World Assembly on Ageing. Madrid, 8-12 April 2002. Publication A/CONF.197/9. New York : United Nations.

United Nations Economic and Social Commission for Asia and the Pacific (ESCAP). 1996. Added Years of Life in Asia: Current Situation and Future Challenges. ST/ESCAP/1688. New York: United Nations.

1997. International and Regional Mandates on Ageing. ST/ESCAP/1807. United Nations.

United Nations General Assembly. 2001. Road Map Towards the Implementation of the United Nations Millennium Declaration. New York: United Nations Department of Public Information.

United Nations International Research and Training Institute for the Advancement of Women (INSTRAW). 1993. The Situation of Elderly Women: Available Statistics and Indicators. Santo Domingo, Dominican Republic: United Nations INSTRAW.

1999. "Introduction: Ageing as a women's issue," in Ageing in a Gendered World, United Nations International Research and Training Institute for the Advancement of Women (INSTRAW). Santo Domingo, Dominican Republic: INSTRAW, pp. v-xii.

United Nations Population Division. 1999. Population Ageing 1999 (Wall Chart). ST/ESA/SER.A/ 179. New York: United Nations .

- 2002. World Population Ageing 1950-2050. ST/ESA/SER.A/207. New York: United Nations.

United Nations Population Fund (UNFPA). 1998. The State of the World Population 1998: The New Generations. New York: UNFPA.

- 2000. The State of the World Population 2000: Lives Together, Worlds Apart, Men and Women in a Time of Change. New York: UNFPA.

-2002a. Population Ageing and Development: Social, Health and Gender Issues. UNFPA.

2002b. Situation and Voices: The Older Poor and Excluded in South Africa and India. New York: United Nations.

Verbrugge, Lois. 1985. "Gender and health: An update on hypotheses and evidence," Journal of Health and Social Behavior 26(3): 156-182.

- 1989. "The twain meet: Empirical explanations of sex-differences in health and mortality," Journal of Health and Social Behavior 30(3): 282-304.

Verbrugge, L. M. and D. L. Wingard. 1987. "Sex differentials in health and mortality," Women * Health 12(2): 103-145.

Waldron, Ingrid. 1985. "What do we know about sex differences in mortality: A review of the literature," Population Bulletin of the United Nations 18: 59-76.

- 1986. "The contribution of smoking to sex differences in mortality," Public Health Reports 101(2): 163-173.

-1995. “Contributions of changing gender differentials in behaviour to changing gender differences in mortality," in D. Sabo and G. Gordon (eds.), Men's Health and Illness: Gender, Power and the Body. London: Sage Publications.

Wolf, Margery. 1972. Women and the Family in Rural Taiwan. Stanford: Stanford University Press. 
World Bank. 1994. Averting the Old Age Crisis: Policies to Protect the Old and Promote Growth. Oxford, England: Oxford University Press.

World Health Organization (WHO). 2001. Men, Ageing and Health. WHO/NMH/NPH/01.2. Geneva: WHO.

Yount, K M. Forthcoming. "Women, gender, and aging as a segment of the lifecycle in Arab societies," Encyclopedia of Women in Islamic Cultures. Leiden: Brill Academic Publishers.

Zeng Yi, Liu Yuzhi, and Linda George. 2003. "Gender differentials of the oldest old in China," Research on Aging 25(1): 65-80.

Zimmer, Zachary, Josefina Natividad, Mary B. Ofstedal, and Hui-Sheng Lin. 2002. "Physical and mental health of the elderly," in Albert Hermalin (ed.), The Well-Being of the Elderly in Asia. Ann Arbor, MI: The University of Michigan Press. 